\title{
КИШЕЧНЫЕ БИОМАРКЕРЫ САХАРНОГО ДИАБЕТА 2 ТИПА
}

\author{
Харчилава Л.Д., Демидова Т.Ю., Лобанова К.Г.
}

Российский национальный исследовательский медицинский университет имени Н.И. Пирогова

ЦЕЛЬ: определить характерные изменения состава кишечной микробиоты (KM) у пациентов с впервые выявленным сахарным диабетом 2 типа (СД2)

МАТЕРИАЛЫ И МЕТОДЫ: 50 пациентам с вПервые выявленным СД2 проводилось генетическое исследование кишечного метагенома человека - 16S pPHK секвенирование.

РЕзУльтАТЫ: среди пациентов, включенных в исследование $46 \%$ ( $\mathrm{n}=23)$ - мужчины, 54\% ( $\mathrm{n}=27)-$ женщины. Средний возраст составил 54,8 $\pm 11,7$ года (95\% ДИ 51,4-58,1), медиана гликемии натощак 12,01 ммоль/л [8,5; 18,2], средний уровень гликированного гемоглобина 9,0 2,0\% (95\% ДИ 8,4-9,6).

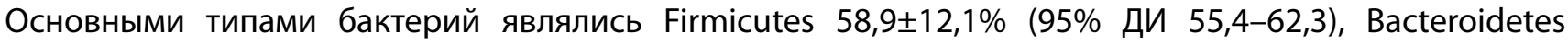
30,6 $\pm 13,2 \%$ (95\% дИ 26,9-34,4), Proteobacteria 2,81\% [1,52; 4,13], Actinobacteria 1,08\% [0,44; 3,02], Verrukomicrobia $0,85 \%[0,14 ; 3,36]$.

у 92,0\% соотношение Firmicutes/Bacteroidetes >1, так как доминирующим типом являлись Firmicutes, Me 1,82 [1,2;3,0]. Также среди пациентов с впервые выявленным СД2 отмечалось су-

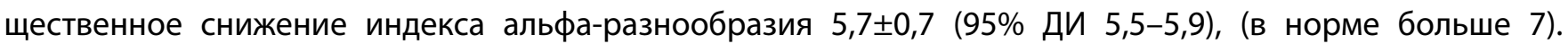
В ходе корреляционного анализа, было выявлено, что при повышении уровня Bacteroidetes индекс альфа-разнообразия снижался $(r=-0,37, p<0,05)$, при повышении Firmicutes - повышался $(r=0,48, p<0,05)$.

В большинстве случаев наблюдалось снижение бактерий, препятствующих развитию СД2: у 94,0\% отмечалось снижение Coprococcus, у 84,0\% - Akkermansia, у 70,0\% - Bacteroides, у 58,0\% - Faecalibacterium, у 52,0\% - Biffidobacterium, у 42,0\% - Roseburia, у 38,6\% - Lactobacterium, 30,0\% - Eubacterium. Tакже характерным изменением у пациентов с впервые выявленным СД2 являлось снижение уровня бактерий, препятствующих развитию ожирения: у 98,0\% пациентов отмечалось снижение Christensenella.

При проведение корреляционного анализа было выявлено, что у людей с более высоким уровнем $\mathrm{HbA}_{1 c}$ наблюдалось снижение уровня Faecalibacterium ( $\left.\mathrm{r}=-0,31, \mathrm{p}<0,05\right)$, а у людей с более высоким индексом массы тела отмечалось повышение уровня Roseburia( $r=0,42, p<0,05)$. Кроме того, установлена прямая зависимость между Faecalibacterium и Roseburia $(\mathrm{r}=0,40, \mathrm{p}<0,05)$. Также была обнаружена обратная корреляционная связь между уровнем гликемии натощак и Faecalibacterium $(r=-0,33, p<0,05)$,

Выводы: таким образом, характерными изменениями у пациентов с впервые выявленным СД2 являются преобладание Firmicutesнад Bacteroides, снижение индекса альфа-разнообразия, снижение бактерий, препятствующих развитию СД2. 